\title{
Young-of-the-year recruitment does not predict the abundance of older age classes in black rockfish in Barkley Sound, British Columbia, Canada
}

\author{
Dana R. Haggarty ${ }^{1,4}$, Katie E. Lotterhos ${ }^{2}$, Jonathan B. Shurin ${ }^{3}$ \\ ${ }^{1}$ Biodiversity Research Centre, University of British Columbia, 112-2212 Main Mall Vancouver, BC V6T 1Z4, \\ Canada \\ ${ }^{2}$ Department of Marine and Environmental Sciences, Northeastern University Marine Science Center, Room \\ 430 Nahant Rd, Nahant, MA 01908, USA \\ ${ }^{3}$ University of California at San Diego, 9500 Gilman Dr., La Jolla, CA 92093, USA \\ ${ }^{4}$ Present address: Pacific Biological Station, Fisheries and Oceans Canada, 3190 Hammond Bay Rd, Nanaimo, \\ BC V9T $1 \mathrm{~K} 6$, Canada
}

*Corresponding author: danahaggarty@gmail.com

This is the final accepted manuscript of a paper originally published in Marine Ecology Progress Series. You may find the final, formatted version at 10.3354/meps12202.

\section{ABSTRACT:}

Recruitment and connectivity are important criteria for designing effective marine protected areas, as coastal fish populations must be sustained by settling juveniles. However, patterns of recruitment are difficult to observe, and adults and juveniles may occupy distinct habitats. We examined patterns of adult black rockfish Sebastes melanops abundance with respect to habitat and spatiotemporal variability in recruitment of young-of-the-year (YOY) to determine how these variables influence population density in and around a rockfish conservation area (RCA). For most year classes, there was no relationship between the density of YOY and the density of $1 \mathrm{yr}$ olds or the density of adults, and instead habitat variables such as topological complexity and the amount of rocky substrate predicted adult black rockfish abundance. For 1 year class of moderate abundance at the YOY stage but high abundance at the 1 yr old stage, a significant relationship between 1 yr olds and subsequent adults was observed. We surmise that over- winter survival of YOY fish may be an important determinant for year-class strength in black rock- fish. Although a companion study found low recruitment of YOY inside the RCA, our data indicate that the density of many species of rockfish was higher inside the RCA. These results highlight how the density of adults can be determined by post-recruitment processes such as movement into suitable habitat and mortality, rather than by recruitment of YOY, and have implications for the design of marine reserve networks. 


\section{INTRODUCTION}

Marine protected areas (MPAs) are implemented to restore and conserve depressed populations of marine fishes and to support the sustainability of fisheries (Sale et al. 2005, Gaines et al. 2010). Worldwide, evidence is mounting that biomass of fishes and invertebrates increases inside well-designed re-serves (Hamilton et al. 2010, McCook et al. 2010, Russ \& Alcala 2011, Edgar et al. 2014). However, the effectiveness of marine reserves varies widely. Reserves need to be evaluated because ineffective reserves can lead to a false sense of security and hamper or prevent other effective management actions (Allison et al. 1998, Sale et al. 2005).

Because an MPA must receive sufficient new recruits or migratory individuals for populations within the reserve to be sustained (Carr \& Reed 1993, Planes et al. 2000, Halpern \& Warner 2003, Gaines et al. 2010), spatial variability in the supply of young-ofthe-year (YOY) may contribute to the effectiveness of MPAs and determine how quickly populations rebound in response to protection (Grorud-Colvert \& Sponaugle 2009, Wen et al. 2013). Wen et al. (2013) found that the adult densities of 2 targeted fish species were 2 to 3 times higher in reserves in Australia that included YOY recruitment 'hotspots' than in reserves that did not include hotspots. Situating reserves in areas receiving large inputs of recruits may be important to their success at promoting population recovery.

On the other hand, post-recruitment density- dependent factors, such as movement, growth, and mortality, can dampen the effect of recruitment (Carr \& Syms 2006). If recruitment limitation is a major determinant of population variation, adult population size should track recruitment intensity with some lag in time for growth. Alternatively, if post-recruitment processes obscure the signal of recruitment intensity, adult population size should be independent of recruitment intensity (Caley et al. 1996), although apparent correlations may arise if variables that influence post-recruitment mortality also influence adult abundance, such as temperature. Uncertainty about how recruitment of YOY and post-recruitment processes influence fish populations complicates the management and conservation of reef fishes. Post- settlement processes dampened the effects of high recruitment in hawkfish Paracirrhites arcatus in Hawaii, USA (DeMartini et al. 2013), as well as bicolor damselfish Stegastes partitus in marine reserves in the Florida Keys, USA (Grorud-Colvert \& Sponaugle 2009). Spatial scale is also an important consideration. Caselle et al. (2010a) found that abundance of adult kelp bass Paralabrax clathratus was predicted by larval supply at regional levels, but this relation- ship broke down at finer scales where recruitment and adult survivorship were density-dependent. Abundances of larval (Ralston \& Howard 1995) or YOY rockfishes (Laidig et al. 2007) have been related to strong cohorts evident in the fishery at very broad scales; however, recruitment signals in adult temper-ate reef fish populations at finer scales has not been well studied (Carr \& Syms 2006). Research is needed to tease apart the relative importance of YOY recruitment and post-recruitment processes to the spatial distribution of adult populations, especially in the context of the efficacy of marine reserves. 
Between 2004 and 2007, a network of 164 rockfish conservation areas (RCAs) was implemented in British Columbia, Canada, to help conserve overfished populations of inshore rockfishes (genus Sebastes) (Yamanaka \& Logan 2010, Lotterhos et al. 2014). The age structure of rockfish populations is generally characterized by overrepresentation of a few strong recruitment cohorts because they are long-lived, slow-growing, and late to mature, with sporadic reproduction (Love et al. 2002). This pattern of population dynamics is known as the 'storage effect,' whereby strong recruitment events are 'stored' in the adult population and disproportionally contribute to future generations (Warner \& Chesson 1985). Capturing spatial and temporal variation in recruitment in space and time may therefore be particularly important to the design of conservation areas for the protection of rockfishes.

In this study, we tested predictors of adult black rockfish S. melanops abundance at sites where juvenile recruitment had been previously quantified in Barkley Sound, British Columbia. Predictors included habitat, previous YOY abundance, and previous 1 yr old (OYO) abundance. Black rockfish can live to be 50 yr old, reach $50 \%$ maturity at 6 to $7 \mathrm{yr}$ of age, and occupy relatively small home ranges of $0.55 \mathrm{~km}^{2}$ (Love et al. 2002, Parker et al. 2007). Juvenile black rockfish settle into nearshore habitats such as kelp forests and eelgrass meadows and move into deeper rocky habitats as they grow (Love et al. 2002). Lotter- hos \& Markel (2012) and our companion study Markel et al. (2017 this Volume) monitored YOY rockfish recruitment at kelp forest sites in Barkley Sound from 2006 to 2009. Sites were distributed throughout the sound in 6 different regions, including inside the Broken Group Islands RCA (Markel et al. 2017). Recruitment was highly variable among sites and years, and strong in 2006 when mean abundance of YOY recruits was 2 to 8 times higher than in other years (Markel 2011). Genetic analysis of the 2006 cohort showed that despite the high abundance of recruits, genetic diversity was low and the incidence of siblings was high, indicating a 'sweepstakes' recruitment event whereby a few adults achieved high re-productive success (Lotterhos \& Markel 2012). In addition, sites sampled inside the RCA had lower recruitment rates in 2006 than those outside of the RCA (Markel et al. 2017). However, it remained un- known whether the large 2006 cohort recruited to the adult population or if post-settlement processes reduced its impact on the population dynamics. In addition, it remained unknown whether the spatial pattern of recruitment intensity throughout Barkley Sound corresponds to variability in adult population density, especially in the context of the RCA.

In this study, we tested the hypothesis that year-class abundance is a predictor of adult black rockfish populations. To evaluate this hypothesis more explicitly, we measured the variance in adult abundance explained by habitat, geography, YOY abundance, and OYO abundance. Finally, we tested the hypothesis that adult rockfish abundance inside the Barkley Sound RCA would be lower than outside the RCA, based on the low recruitment observed in that area in 2006.

MATERIALS AND METHODS 


\section{Study system}

This study took place in Barkley Sound $\left(48^{\circ} 50^{\prime} \mathrm{N}, 125^{\circ} 22^{\prime} \mathrm{W}\right.$ ) on the southwest coast of Vancouver Island, Canada. In the center of the sound lies the Broken Group Islands (BGI), within the Pacific Rim National Park Reserve as well as an RCA (Fig. 1). Sampling sites were distributed across Barkley Sound in the following 5 regions, at a density of 6 sites per region in each year: George Fraser Island (GF), Loudoun Channel (LC), Broken Group Islands (BGI), Deer Group Islands (DG), and 'Prasex' (PE, from Prasiola Point to Execution Rock on Vancouver Island; Fig. 1). Regions are separated from each other by at least $2 \mathrm{~km}$ and by 3 deep water channels, viz. Loudoun, Imperial Eagle, and Trevor Channels (Fig. 1).
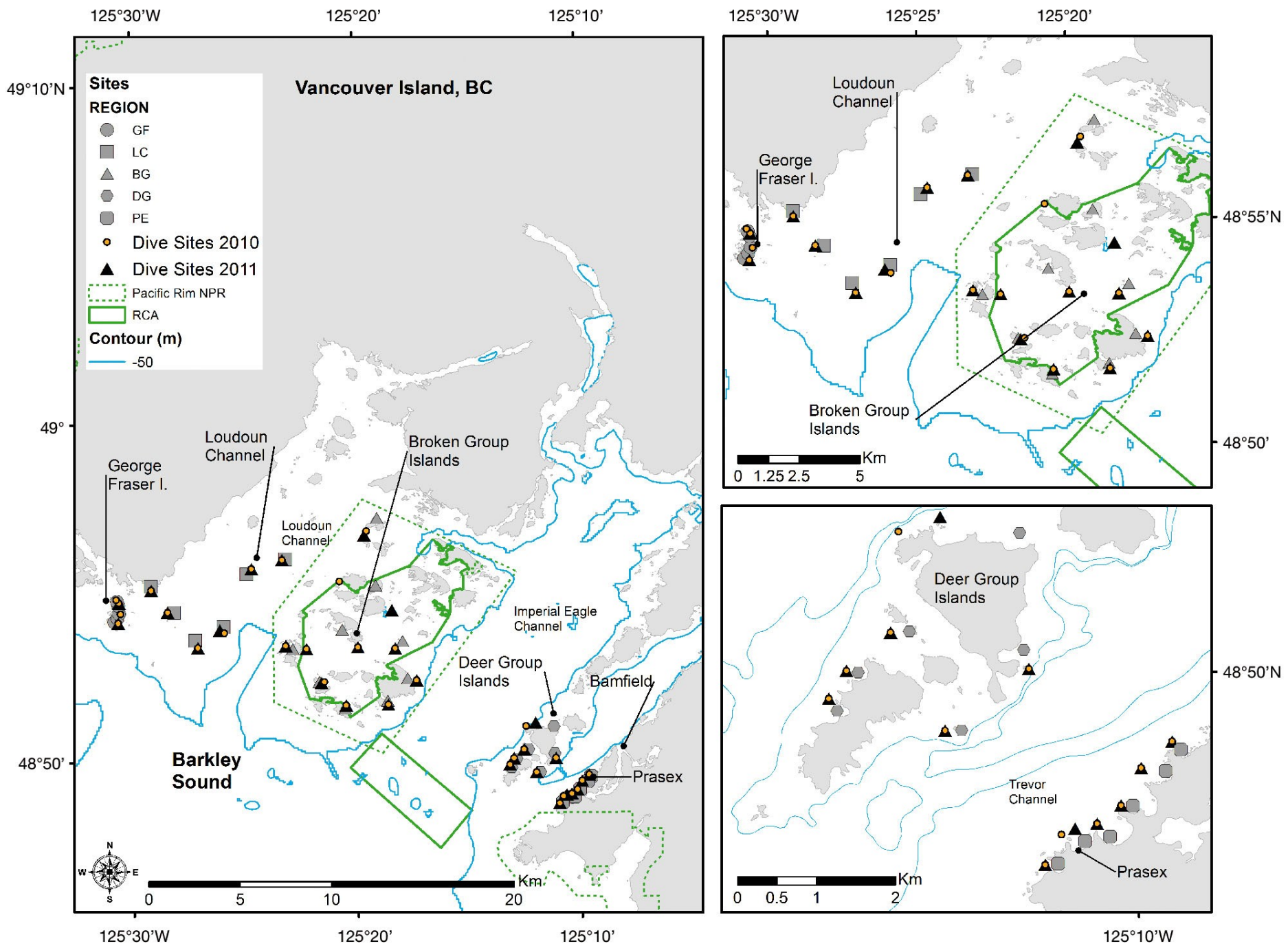

Fig. 1. Sampling sites in Barkley Sound, British Columbia, Canada. Standard monitoring units for the recruitment of fish (SMURF) sites (grey) were sampled in 2005 to 2008. Dive sites were sampled in 2010 (orange circles) and 2011(black triangles). GF: George Fraser Island, LC: Loudoun Channel, BG: Broken Group Islands, DG: Deer Group Islands, PE: Prasex, RCA: rockfish conservation area, NPR: National Park Reserve 


\section{Recruitment of YOY and OYO}

In this study, recruitment is defined as the mean number of YOY or OYO rockfish caught in Standard Monitoring Units for the Recruitment of Fishes (SMURFs; Ammann 2004). These have been used to measure coastal fish recruitment in British Columbia (Markel 2011, Lotterhos \& Markel 2012) and California (Ammann 2004, Caselle et al. 2010a,b). SMURFs consisted of a $1.0 \mathrm{~m} \times 0.35 \mathrm{~m}$ cylinder of plastic gar-den fencing material (2.5 $\mathrm{cm} \times 2.5 \mathrm{~cm}$ mesh), stuffed with strips of plastic snow-fence material that serves as habitatforjuvenile fishes. SMURFs were placed in physical contact with kelp and sampled in all 5 regions from 2006 to 2009, approximately every 2 wk between May and August (Markel et al. 2017). Note that because of their placement in kelp, in this study SMURFs measured a snapshot of juvenile fish density in the kelp forest, rather than being deployed in minimal habitat in order to measure settlement (as in Ammann 2004). Furthermore, OYO black rockfish were caught unexpectedly in SMURFs in May and June (before YOYs started to recruit; in June they moved into deeper habitat) and we leveraged these data for analysis. OYOs and YOYs could be distinguished by body shape and pigmentation (Fig. S1 in Supplement 1 at www.intres.com/articles/suppl/m574p113_supp1.pdf) as well as by size and time of catch (Fig. S2). We also found a strong correspondence in year-class strength between SMURF and visual surveys for both YOY and OYO, indicating that OYO abundance in SMURFs was representative and unbiased (Fig. S3). For YOY, we calculated the mean abundance at that site for each sampling year between 2006 and 2008 (June to July) and for OYO between 2007 and 2009 (mean black rockfish per SMURFsite,Year in May to June). There were 3 sites in the BGI that were only monitored in 2006 (Hand, Turrett, and Chalk).

Site-level analysis of recruitment (YOY) to OYO

We analyzed the relationship between YOY and OYOs for each cohort (2006-2008) with a general linear mixed model (function 'Imer' in R, R Development Core Team 2008). The model included log- transformed OYO as a response variable, and the predictor variables of log-transformed YOY as a co-variate, Cohort as a fixed effect, and Site as a random effect. We examined the residuals using fitted vs. observed plots and using the autocorrelation function (function 'acf' in R) to ensure that there was no autocorrelation in the dataset. If an inter-action was present, we examined the relationship between OYO and YOY for each cohort separately using Region as a random effect. Linear mixed models were fit by restriction maximum likelihood t-tests using Satterthwaite approximations to the degrees of freedom (ImerMod in R, see R Markdown in Supplement 2 at www.int-res.com/articles/suppl/m574p113_supp2.pdf).

Because patterns of migration of YOY are generally unknown, in addition to this sitelevel analysis we also plotted the overall abundance of each cohort from the YOY to the OYO stage to see if they were congruent with the strength of YOY year classes. 
In 2010 and 2011, we measured adult rockfish density using SCUBA surveys close to the locations sampled for recruiting rockfishes with SMURFs (Lotter- hos \& Markel 2012, Markel et al. 2017). In Barkley Sound, kelp forests are largely constrained to waters shallower than $6 \mathrm{~m}$. We sampled the rocky reef habitat between 6 and $18 \mathrm{~m}$ deep in closest proximity to each recruitment sampling location. The median distance between pairs of adult survey sites and recruitment sampling locations was $244 \mathrm{~m}$ $(83-1990 \mathrm{~m})$. The most distant pairs arose from a gradual depth gradient and inappropriate adult habitat adjacent to the recruitment sites at 4 locations (Fig. $1 ; 1$ site in DG: Kirby; and 3 sites in the BGI that were only monitored with SMURFs in 2006: Hand, Turret, and Chalk). At 3 of these locations, different dive sites were surveyed in 2010 and 2011 in order to target better habitat (Hand) or to sample closer to the SMURF site (Kirby and Chalk). Rocky reef habitat was identified based on rocky shoreline characteristics, depth contours on nautical charts and depth sounder, and visual observations of the habitat while SCUBA diving.

SCUBA divers sampled 2 (in 2010) or 4 (in 2011) $30 \mathrm{~m} \times 3 \mathrm{~m}$ transects per site distributed between 6 and $18 \mathrm{~m}$ of depth. Upon descending, divers searched for rocky habitat within this depth range. Trained divers identified, counted, and estimated the length of black rockfish as well as all rocky-reef fish found within the transect. The second diver followed the transect line to record depth (measured every $2 \mathrm{~m}$ ), substrate type, and relief and habitat complexity modified from classifications based on Pacunski \& Palsson (2001). From these data, the percent cover of (1) rock (total of bedrock and rocks $>20 \mathrm{~cm}$ in diameter), (2) high complexity (moderate to high irregularity, $>25 \%$ of habitat with crevices), and (3) high relief (vertical relief $>2 \mathrm{~m}$ or walls) habitat was measured. These 3 habitat variables were summed over each transect, divided by the number of observations (15), and calculated as a percent for each transect. We also calculated the mean depth of each transect. The divers swam back to the start while reeling in the line and completed a second transect 3 to $7 \mathrm{~m}$ shallower following the opposite compass bearing. In 2011, divers completed 4 transects per dive following the same procedure, except that subsequent transects were 1.5 to $3 \mathrm{~m}$ shallower and 2 transects were per-formed in each compass bearing.

To calculate density for each species, we summed the number of observations per transect, divided by the area of the transect $\left(90 \mathrm{~m}^{2}\right)$, and multiplied by 100 to give the density per $100 \mathrm{~m}^{2}$. Only fish greater than $8 \mathrm{~cm}$ in length were included in the density estimates.

\section{Adult and habitat transect-level analysis}

We used a general linear mixed model to analyze overall adult abundance as a function of habitat variables at the level of individual transects. We used a principal components analysis (PCA) to summarize the relationships among habitat variables, some of which were highly correlated with each other (here- after: habitat-PC). The general linear 
mixed model included adult abundance as the response variable, the principal components that explained the majority of the variance as predictor variables, and the random effects of site and survey year. The model was fit by REML t-tests using the Satterthwaite approximations to the degrees of freedom (ImerMod in R). We performed model selection using Akaike's information criterion (AIC) and used chi-squared tests to test for significant differences among models.

Site-level analysis of adult abundance

The purpose of this analysis was to determine whether any YOY or OYO year class could significantly explain adult abundance at any site. For this analysis, we used a linear model to analyze adult abundance in each survey year as a function of mean habitat at each site, geography of each site, mean abundance of YOY at that site for each cohort, and mean abundance of OYO at each site for each cohort. Mean habitat at each site was included as the significant PC axes averaged over replicate transects at that site from the transect-level adult and habitat analysis.

For geographic variables, we estimated exposure as fetch, tidal velocity, and distance from the mouth of the sound using ArcGIS 10.2.2 (ESRI). We ran an ArcGIS fetch tool (E. Gregr pers. comm.) to estimate the mean northwest (winter) and southeast (summer) exposure for each dive site. For each sampling site (point), the fetch tool draws a full circle of 72 lines spaced every $5^{\circ}$ and measuring up to $200 \mathrm{~km}$ long and calculates the distance to the nearest land for each line. For northwest fetch, we summed the distance for bearings 295 to $335^{\circ}$ and calculated the mean of the 9 observations. For southeast fetch, we summed the distance for bearings 90 to $130^{\circ}$ and calculated the mean of the 10 observations. Northwest fetch represents the exposure of a site to the predominant winter winds on the west coast of Vancouver Island, while southeast fetch represents a site's expo- sure to the dominant summer wind direction. To calculate the distance between each site and the mouth of the sound, we drew a line across the mouth of the sound and calculated the nearest planar distance between each site and the line in ArcGIS. To estimate the tidal speed per site, we extracted the mean bottom tidal speed from a tidal model (Foreman et al. 2008). We again used principal components analysis to summarize relationships among these correlated variables (hereafter: 'geography-PC') for inclusion in the linear model.

For each survey year, the full linear model included mean adult abundance at each site as a response variable, and the covariates of the following variables at each site: mean abundance of each YOY cohort (2006-2008), mean abundance of each OYO cohort (2006-2008), the first principal component of the habitat-PCA (which explained variance in adult abundance, see 'Results'), and the first principal component of the geography-PCA (which explained the majority of variance in the geography-PCA, see 'Results'). All fish abundances were $\log (x+1)$ trans- formed for analysis. We again used AIC for model selection. If given a choice between dropping one of the YOY predictor variables versus another predictor variable (i.e. dropping each variable would give a similar AIC less than the full model), then we dropped the YOY first based on the principle that the OYO predictors should be more predictive of adult abundance. 


\section{Adult size analysis from visual surveys}

To complement the linear mixed model, we calculated the frequency distribution of size classes in the adults to infer if any given cohort was overrepresented in the adult population. In addition to counting fish, SCUBA divers visually estimated the lengths of the rockfish. Before conducting the surveys, divers were trained in length estimation using laminated model fish of known length until their length estimates were within $10 \%$ of the true length. To con- duct a length-at-age analysis, we collected black rockfish in Barkley Sound in 2010 using hook and line methods and sampled fish for length, weight, sex (when possible), and otoliths using standards approved by the Canadian Council on Animal Care. Some additional black rockfish samples (lengths and otoliths) were obtained from a local sports fisher. Black rockfish samples $(n=51)$ were aged at Fisheries and Oceans Canada's Fish Ageing Lab at the Pacific Biological Station (PBS) using the otolith burnt cross section method of age estimation (MacLellan 1997). A second sample of 41 black rockfish collected in 2006 from the west coast of Vancouver Island and aged using the same methods at PBS (Markel 2011) were also used in the analysis of length-at-age for black rockfish.

\section{RCA evaluation}

Previously, we found that the BGI RCA experienced low recruitment during the exceptionally strong recruitment year of 2006 (Markel et al. 2017). Such recruitment limitation may limit the effective- ness of the RCA. Marine reserves are often evaluated using a response ratio ( $R R$ ) that compares the mean density of fish inside to outside of a reserve (Hedges et al. 1999, Russ et al. 2005, Claudet et al. 2010, Hamilton et al. 2010, Edgar et al. 2014, Haggarty et al. 2016):

$$
R R=\ln \left(\frac{\bar{X}_{\text {in }}}{\bar{X}_{\text {out }}}\right)
$$

While the focus of this study is on black rockfish, if multiple species have higher abundance inside the RCA, this lends more support to the hypothesis that the RCA is working. We calculated the mean density of black rockfish, quillback rockfish Sebastes maliger, copper rockfish S. caurinus, and all inshore rock- fishes combined (those 3 species plus China rockfish S. nebulosus and tiger rockfish S. nigrocinctus), as well as lingcod Ophiodon elongatus and kelp greenling Hexagrammos decagrammus observed on all transects inside and outside of the BGI RCA. 

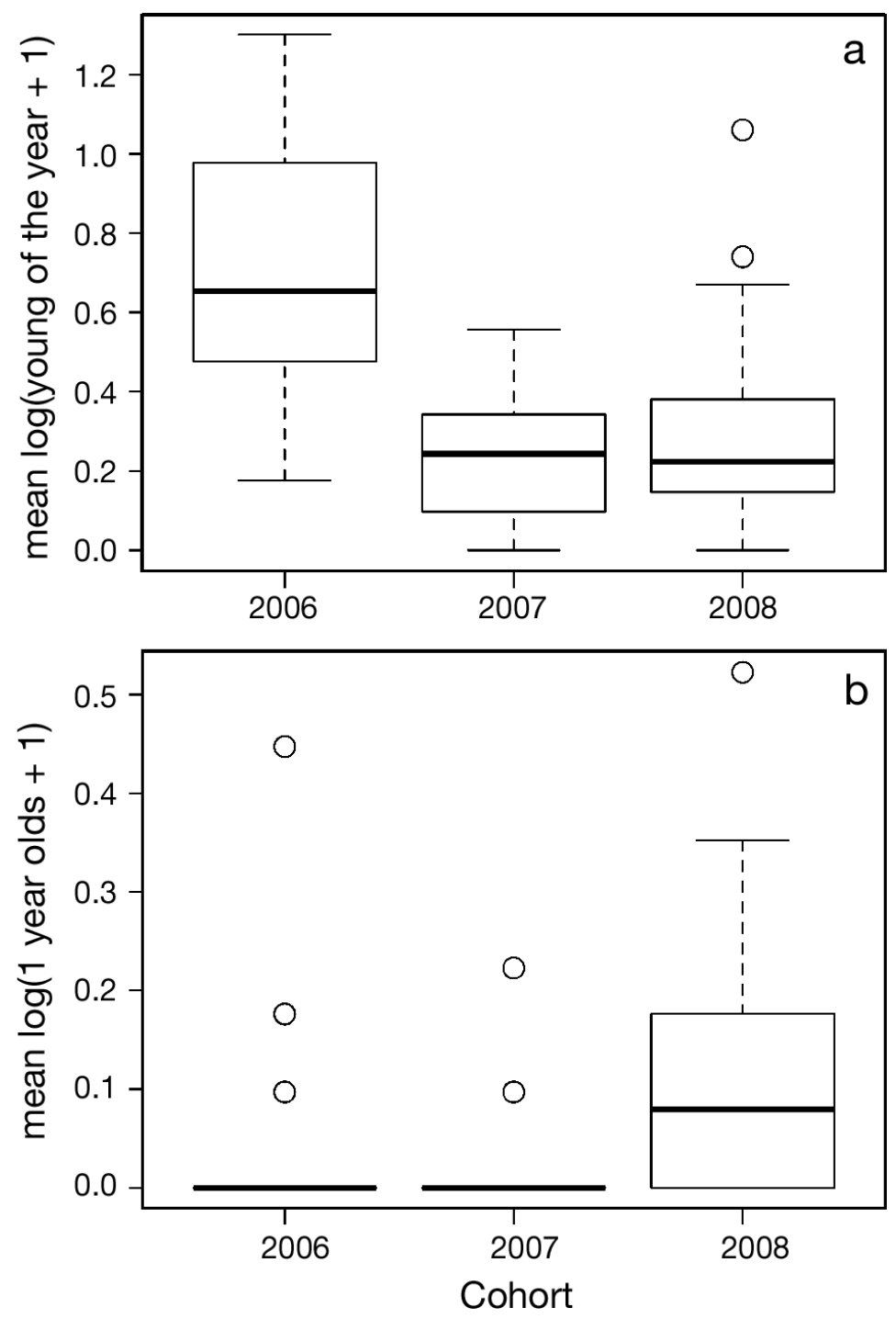

Fig. 2. (a) Average abundance of young-of-the-year black rockfish Sebastes melanops in each cohort across all 30 sites in Barkley Sound. (b) Average abundance of 1 yr olds of the respective cohort (from surveys in the next season). The thick horizontal line represents the median; box limits represent the $25 \%$ and $75 \%$ quantiles; whiskers represent data range exluding outliers; circles represent outliers as determined by the $\mathrm{R}$ function boxplot

\section{RESULTS}

We sampled 65 transects at 32 sites in 2010 and 119 transects at 30 sites in 2011 . In 2011, we only sampled 3 of the 5 sites at GF, since the sites were all close together. In both years, black rockfish were the most commonly observed rockfish, followed by deacon rockfish Sebastes diaconus (recently identified as a sister species of the blue rockfish S. mystinus: Frable et al. 2015), copper rockfish, and quillback rockfish. The mean depth sampled was consistent between the 2 years, with a mean \pm SD depth of $10.6 \pm 2.6 \mathrm{~m}$ in 2010 and $10.2 \pm 2.4 \mathrm{~m}$ in 2011 . 


\section{Recruitment of YOY and OYO}

We found that although 2006 had the overall highest recruitment of YOY, 2008 had the highest overall recruitment of OYOs (Fig. 2). We used an ANCOVA to examine the relationships between OYO and YOY at each site with cohort as a fixed effect, and this model had a significant interaction (Table 1: full model). Therefore, we analyzed this relationship for each cohort separately (Table 1: single models). The 2006 and 2007 cohorts had non-significant relation- ships between YOY abundance in one year and OYO abundance in the next season (Fig. 3, Table 1: Cohort 2006 and 2007 single models). Although 2008 had a significantly positive slope between OYO and YOY abundance (Fig. 3, Table 1: Cohort 2008 full model), this positive relationship was driven entirely by a single site that had high YOY abundance in one year and high OYO abundance in the next (Table 1: Cohort 2008 model without outlier). While we can think of no a priori reason to exclude this single outlying site from the model for 2008 , these results suggest that the relationship between YOY and OYOs at the site level is weak. No autocorrelation was observed in the residuals of these models when site was included as a random effect (see R Markdown in Supplement 2).

Table 1. Results of fixed effects from linear mixed model explaining abundance of 1 yr old (OYO) black rockfish Sebastes melanops at the site level (OYO YOY $\times$ Cohort $+[1 \mid$ Site], where YOY indicates young of the year) and subsequent linear mixed models for each cohort separately; ns: not significant, $* p<0.05$

\begin{tabular}{|c|c|c|c|c|c|c|}
\hline Parameter & Estimate & $\mathrm{SE}$ & df & $t$ & $\mathrm{p}(>|t|)$ & $H_{0}$ \\
\hline \multicolumn{7}{|l|}{ Full model } \\
\hline Cohort 2006 Slope & -0.076 & 0.06 & 76.22 & -1.24 & ns & Slope $=0$ \\
\hline Cohort 2007 Slope & 0.064 & 0.13 & 74.66 & 0.49 & ns & $\begin{array}{l}2007 \text { slope } \\
=2006 \text { slope }\end{array}$ \\
\hline Cohort 2008 slope & 0.23 & 0.10 & 76.65 & 2.374 & $0.02^{*}$ & $\begin{array}{l}2008 \text { slope } \\
=2006 \text { slope }\end{array}$ \\
\hline \multicolumn{7}{|l|}{2006 Model } \\
\hline Slope & -0.06 & 0.068 & 8.86 & -1.00 & ns & Slope $=0$ \\
\hline \multicolumn{7}{|l|}{2007 Model } \\
\hline Slope & 0.004 & 0.057 & 24.89 & 0.07 & ns & Slope $=0$ \\
\hline \multicolumn{7}{|l|}{2008 Model } \\
\hline Slope & 0.21 & 0.10 & 26.71 & 2.09 & $0.047^{*}$ & Slope $=0$ \\
\hline \multicolumn{7}{|c|}{2008 Model without outlier } \\
\hline Slope & -0.07 & 0.11 & 17.16 & -0.65 & ns & Slope $=0$ \\
\hline
\end{tabular}




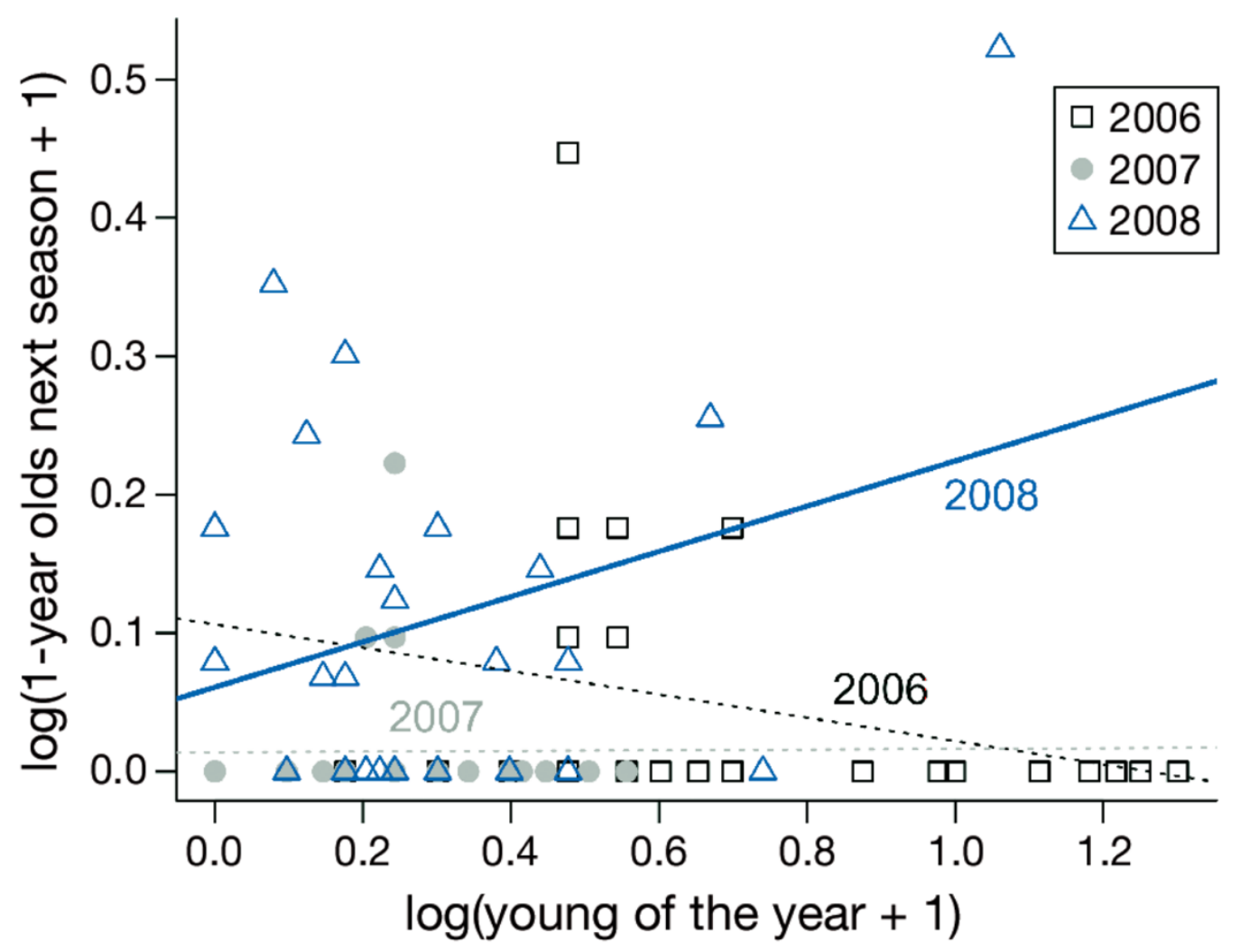

Fig. 3. Relationship between abundance of young-of-theyear black rockfish Sebastes melanops and abundance of $1 \mathrm{yr}$ olds at each site for the 3 cohorts. The slope for 2008 is heavily influenced by a single data point

\section{Adult and habitat transect-level analysis}

were highly correlated with each other and loaded strongly onto the first PC axis (habitat-PC1), while mean depth loaded strongly onto the second PC axis (habitat-PC2, Fig. 4). The third PC axis (habitat-PC3) separated rock and high complexity (Table 2). We used a linear mixed effect model to study the relationship between adult abundance as a function of habitat-PC1, habitat-PC2, and habitat-PC3, with the random effects of year of adult survey and site. No autocorrelation was observed in the model residuals when these random effects were included (Supplement 2). The best model based on AIC included all 3 habitat PCs, but only PC1 was significant (Table 2). Adult abundance increased significantly with PC1 (habitat complexity and percent rock, Fig. $5)$, and there was a nonsignificant positive trend for abundance to increase with depth (Table 2). 


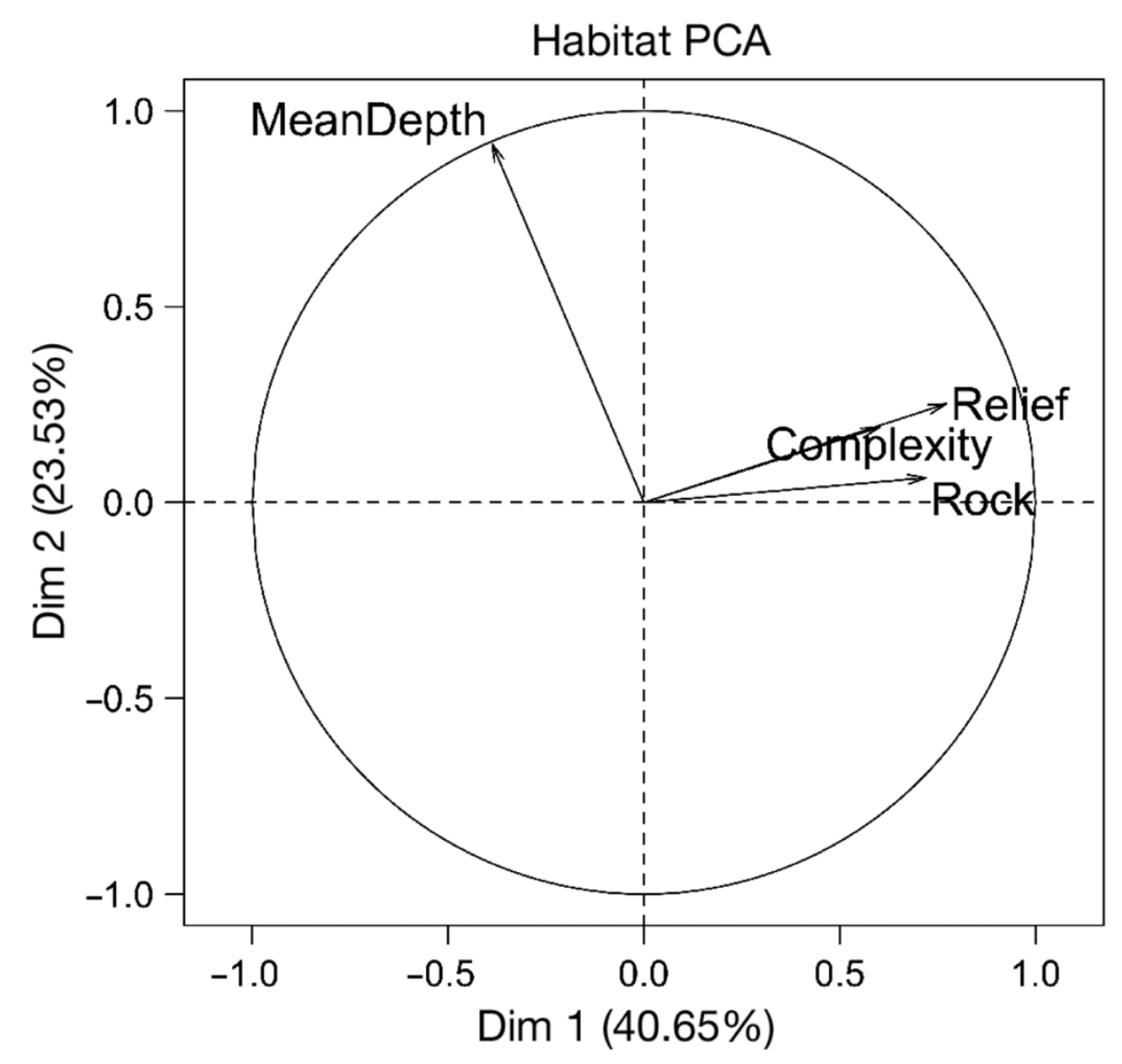

Fig. 4. Visualization of the loadings for the habitat principal components analysis on proportion of rock, high relief, and high-complexity habitat

Table 2. Results from the linear mixed effects model analyzing adult black rockfish Sebastes melanops abundance as a function of habitat principal components (PCS) at the transect level: Adult density (habitat-PC1 + habitat-PC2 + habitat-PC3 + (1|Site $)+(1 \mid$ Year), where $(1 \mid X)$ indicates a random effect; ns: not significant

\begin{tabular}{|cccccc|}
\hline & Estimate & SE & df & $t$ & $\mathrm{p}(>|t|)$ \\
\hline Habitat-PC1 & 0.16 & 0.03 & 176.47 & 4.846 & $<0.001$ \\
Habitat-PC2 & 0.08 & 0.04 & 177.67 & 1.799 & 0.0736 \\
Habitat-PC3 & 0.06 & 0.04 & 179.13 & 1.314 & $\mathrm{~ns}$ \\
\hline
\end{tabular}

Adult abundance site-level analysis

We used a second linear mixed effect model to examine whether mean adult abundance at the site level in each year of the adult surveys could be explained by 
abundance of YOY of that site for each cohort, abundance of OYOs at that site for each cohort, site-level geographic variables, and average habitat variables for that site. The geographic variables included bottom tidal velocity, distance from the mouth of the sound, northwest fetch (winter exposure), and southeast fetch (summer exposure). We summarized these geographic variables with a PCA, and the majority of variance (72\%) was explained by the first PC axis which was positively correlated with tidal velocity and southeast fetch, and negatively correlated with northwest fetch and distance from the mouth of the sound (hereafter 'geo- PC1', Fig. S4 in Supplement 1). Habitat variables were summarized as the mean habitat-PC1 for all transects at that site in the survey year, because of the significance of this predictor in our transect-level analysis. Thus, the full starting model for each adult survey year included the predictors of YOY-2006, YOY-2007, YOY-2008, OYO-2006, OYO2007, OYO- 2008, Habitat-PC1, and Geo-PC1 (note that OYO- 2006 refers to the abundance of fish from the 2006 cohort observed in 2007 when they were $1 \mathrm{yr}$ old, etc.).

For the adult surveys in 2010, the best model included OYO-2007 ( $p=0.12$ ), habitat-PC1 $(p=0.046)$, and geo-PC1 ( $p=0.32$, Table 3$)$. The 2010 model only explained $11 \%$ of the variation in adult abundance, and the model itself was not significant ( $p=0.12$, Table 3 ). Removing OYO-2007 from this model only increased the AIC by 0.863 , demonstrating that it does not substantially improve the explanatory power of the model.

For the adult surveys in 2011, the best model included YOY-2007 ( $p=0.12)$, OYO-2007 ( $p$ $=0.059)$, OYO-2008 ( $p=0.037)$, habitat-PC1 $(p=0.008)$, and geo-PC1 $(p=0.10)$. The 2011 model explained $52 \%$ of the variation in adult abundance and was highly significant $(p<0.001$, Table 3 ). Removing YOY-2007 or geo-PC1 from this model only increased the AIC by 1.1 or 1.5, respectively, demonstrating that they do not substantially improve the information content in the model. However, removing OYO2008 or OYO-2007 increased AIC by more than 2, indicating that they did contribute information content to the model. The significant relationship between OYO abundance of the 2008 cohort and adult abundance in 2011 was positive, although there were some sites where OYOs were not observed and still had high adult abundance in 2011 (Fig. 6, see Fig. S5 for all OYO cohorts). The mean square of OYO-2008 was about twice that of habitat-PC1 (1.18 vs. 0.57) and the slope with adult abundance was over 4 times that of habitat PC-1 (1.01 vs. 0.23), indicating that the abundance of OYOs from the 2008 cohort explained more of the variation in adult abundance than habitat did in 2011 (Table 3). 


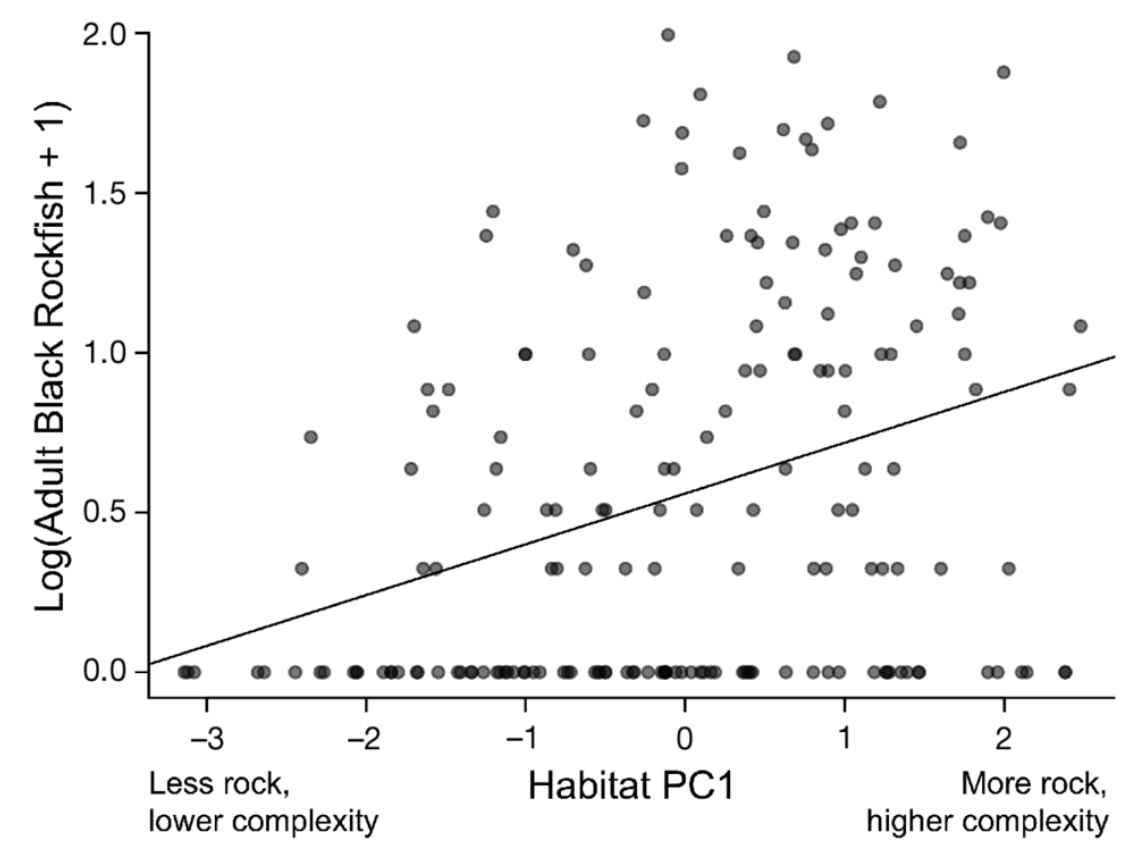

Fig. 5. Relationship between adult black rockfish Sebastes melanops abundance and the first principal component from the habitat principal components analysis

Table 3. Results from general linear mixed models of sitelevel adult black rockfish Sebastes melanops abundance as a function of young-of-the-year (YOY) abundance of each cohort, $1 \mathrm{yr}$ old (OYO) abundance of each cohort, habitat variables, and geographic variables. Note that OYO2007, for example, refers to the abundance of fish from the 2007 cohort caught 1 yr later in 2008; ns: not significant

\begin{tabular}{|lcccc|}
\hline & Estimate & $\mathrm{SE}$ & $t$ & $\mathrm{p}(>|t|)$ \\
\hline 2010 best model & & & & \\
OYO_2007 & 3.27 & 2.03 & 1.607 & $\mathrm{~ns}$ \\
Habitat-PC1 & 0.18 & 0.09 & 2.110 & 0.0455 \\
Geo-PC1 & 0.06 & 0.06 & 1.021 & $\mathrm{~ns}$ \\
Adj. R ${ }^{2}$ 0.11 & & & & \\
F-statistic: 2.16 on 3 and 24 df, $\mathrm{p}=0.12$ & & \\
2011 best model & & & & \\
YOY_2007 & 0.56 & 0.35 & 1.59 & $\mathrm{~ns}$ \\
OYO_2007 & -2.31 & 1.15 & -2.00 & 0.059 \\
OYO_2008 & 1.02 & 0.45 & 2.23 & 0.037 \\
Habitat-PC1 & 0.23 & 0.08 & 2.96 & 0.008 \\
Geo-PC1 & 0.06 & 0.03 & 1.70 & $\mathrm{~ns}$ \\
Adj. R ${ }^{2}: 0.529$ & \multicolumn{5}{l}{} & \\
F-statistic: 6.615 on 5 and 20 df, $\mathrm{p}<0.001$ & \\
& & & & \\
\hline
\end{tabular}




\section{Length analysis}

To examine whether the results from these models were consistent with the large 2006 year class being underrepresented in the adult population and the moderate 2008 year class being overrepresented in the adult population, we examined the distribution of fish lengths estimated by trained divers and com- pared this to the expected length-atage from the von Bertalanffy growth curve (Fig. S6). The expected mean size of a 1, 2, 3, 4 , and $5 \mathrm{yr}$ old black rockfish is $11,16,24,27$, and $32 \mathrm{~cm}$, respectively (Fig. S6). In 2010, the size frequency of fish inside and outside of the RCA were very similar, and no size classes dominated either distribution (Fig. 7a). In 2011, we observed a peak in the length histogram for 20-25 cm black rockfish inside the RCA and 20-30 cm outside the RCA, which is consistent with 2008 being a strong year class (Fig. 7b). In 2011 we did not observe a peak in the length frequency histogram at $30-35 \mathrm{~cm}$, which is consistent with the lack of representation of the 2006 year class in the adult population (Fig. 7b).

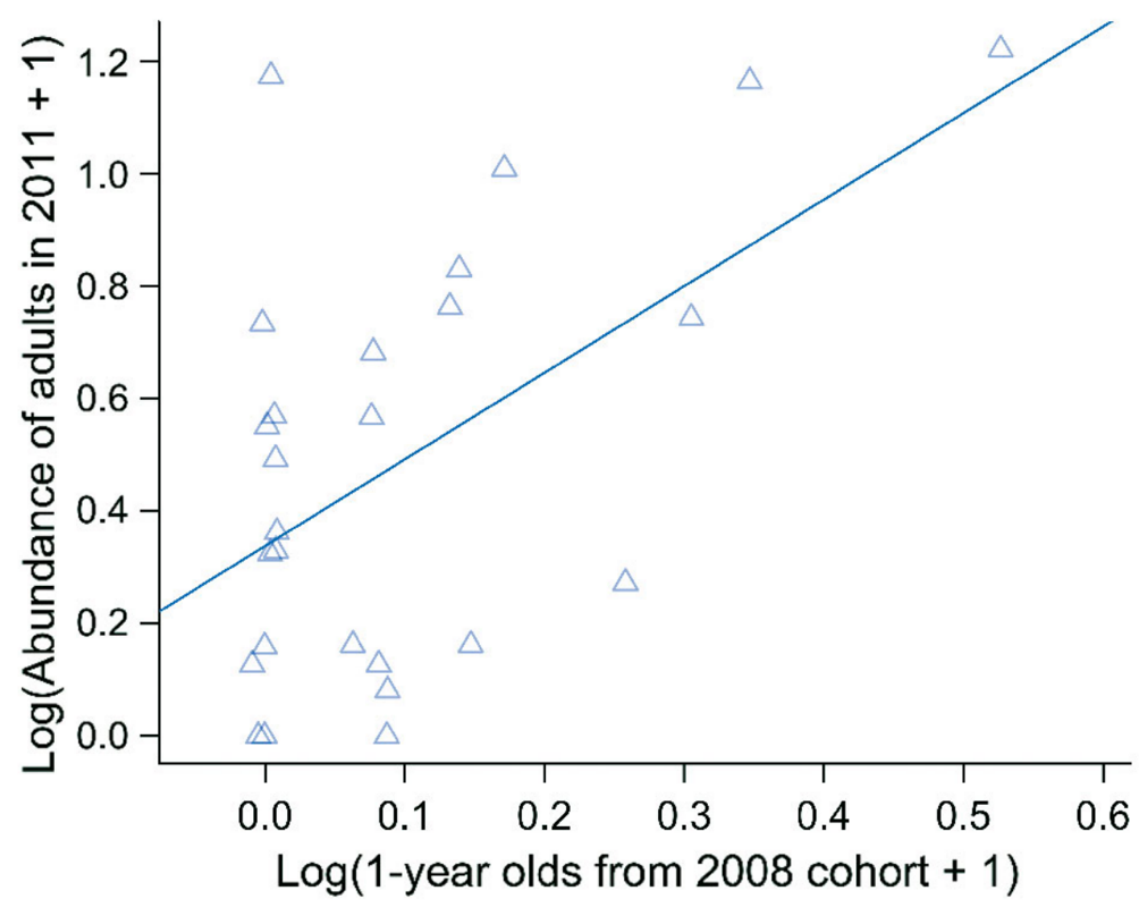

Fig. 6. Relationship between abundance of 1 yr old black rockfish Sebastes melanops from the 2008 cohort (observed in 2009) across all sampling sites in Barkley Sound. See Fig. S5 in Supplement 1 at www. int-res. com/articles/ suppl/ m574 p113 _ supp1. pdf for this relationship for all cohorts

RCA RR analysis

The average RR of all rockfishes (black, quillback, copper rockfishes and inshore rockfishes combined) was $>0$, indicating higher densities inside the RCA than outside. The RRs of kelp greenling and lingcod were $<0$, indicating lower densities of these 
species inside the RCA than outside (Fig. 8).

We tested whether this result was only a habitat effect, i.e. not a direct effect due to reduced fishing pressure but an indirect effect due to more suitable habitat within the RCA. We found that sites inside the RCA had slightly less suitable habitat than sites outside the RCA, but the difference was not significant (Welsh 2-sample t-test with habitat-PC1: mean of Inside $=-0.31$, mean of Outside $=0.06, t=-1.27, p=0.21$ ), suggesting that the higher RR was a direct result of reduced fishing pressure.

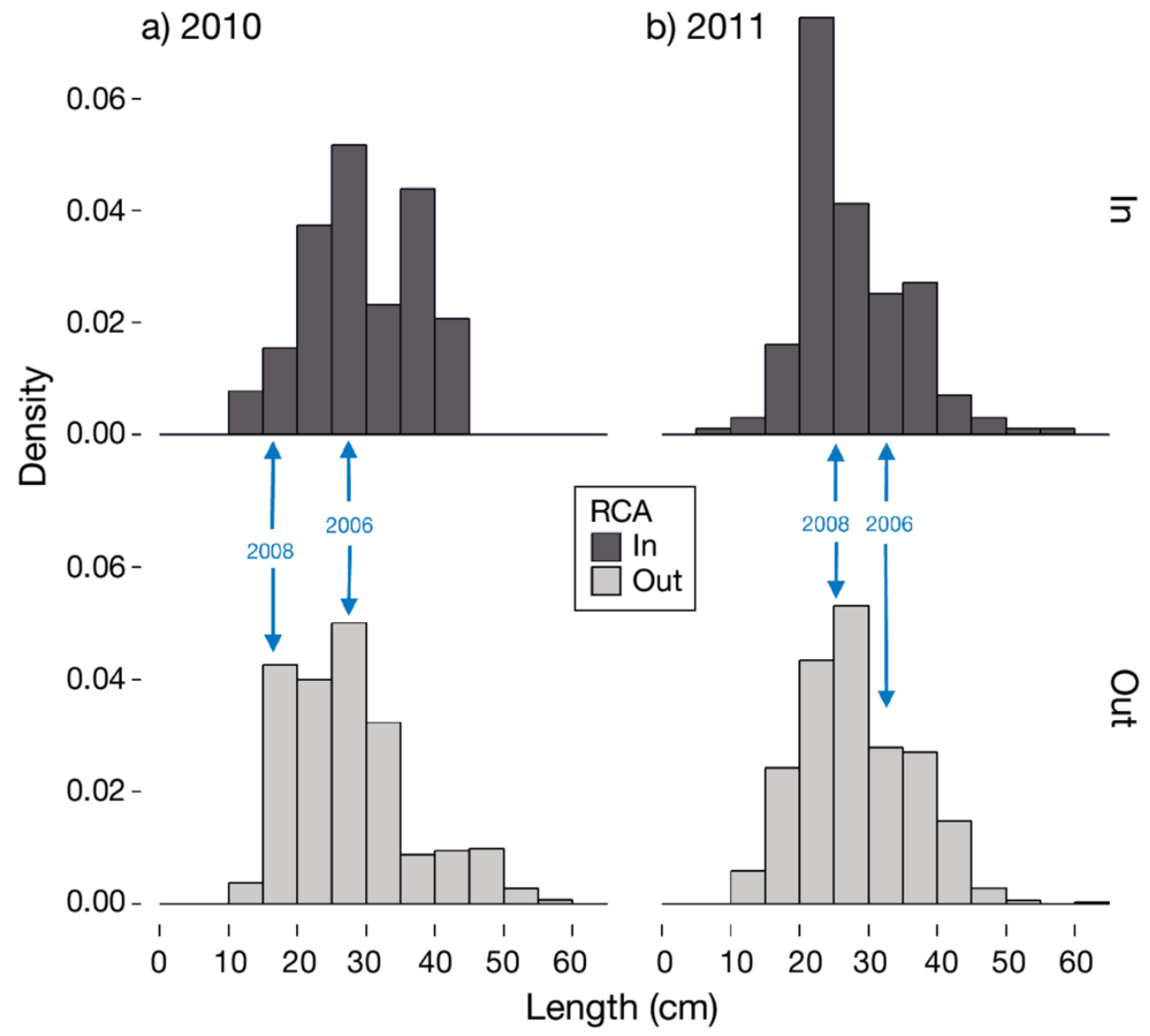

Fig. 7. Length distributions of adult black rockfish Sebastes melanops both inside and outside the rockfish conservation area (RCA), in the adult survey years of (a) 2010 and (b) 2011. The arrows indicate the expected size of a fish from the indicated cohort, based on length-at-age relationships 


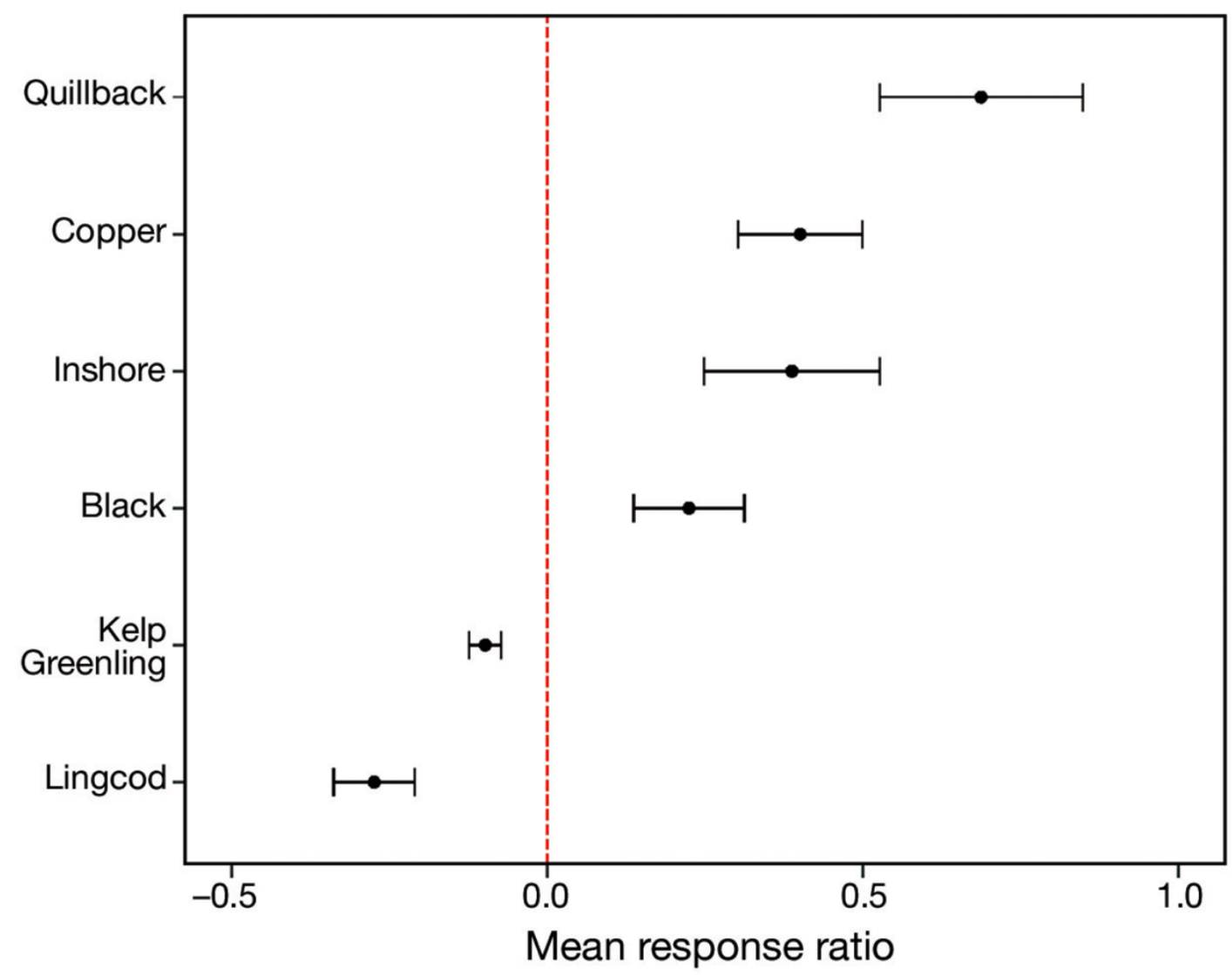

Fig. 8. Mean response ratio of reef fish species in the Broken Group Islands rockfish conservation area (RCA) as compared to all sites in Barkley Sound outside of the RCA ( $n=2)$. A ratio of 0 (red dashed line) indicates no difference. Error bars are SE

\section{DISCUSSION}

Understanding how processes that determine the spatiotemporal variability in YOY recruitment inter- act with processes that determine the variability of sub-adults and adults has implications for the design and assessment of MPAs. In Barkley Sound, post- recruitment processes such as mortality and movement into suitable habitat dampened any signal of YOY recruitment strength in black rockfish. The level of YOY recruitment generally did not explain spatial variation in adult densities, and in the year of highest recruitment (2006), a negative relationship between the abundance of YOY and adults was observed. Our results illustrate how post-recruitment mortality and ontogenetic movements of fish may erase the legacy of a strong YOY cohort, particularly at finer scales (e.g. Gillanders et al. 2003). However, we did find that a strong OYO cohort can explain spatial variation in adult density at a fine scale. 
Oceanographic conditions, specifically warmer temperatures at parturition and during the pelagic phase, and strong upwelling during settlement that affects larval transport, have been related to variation among years in black rockfish YOY recruitment (Lotterhos \& Markel 2012). These findings were consistent with other studies in the US, which have led some to suggest that year-class strength for rockfishes is primarily set during the larval phase (Ralston \& Howard 1995, Yoklavich et al. 1996, Laidig etal. 2007). Laidig et al. (2007) used a 20 yr dataset of YOY rockfish surveys to show that levels of recruitment of black and blue rockfishes as well as yellowtail rockfish Sebastesflavidus in northern California (USA) varied synchronously and were largely determined by oceanographic conditions in February and March. Furthermore, in northern California, year-specific adult yellowtail rockfish landings at nearby ports were significantlycorrelated tolevels ofYOY recruitment. However, we found no relationship between YOY recruitment and the abundance of adults at a much higher latitude in Barkley Sound. Our data indicate that cohort strength may be set at the OYO stage.

A number of processes may obscure the relation- ship between the abundance of YOY and OYOs. Little is known about ontogenetic movements over the first year of life in juvenile rockfishes, and migration to different habitats may obscure the correlation between YOY and older year classes. OYOs were caught in SMURFs, especially in the late spring and early summer, which led us to conclude that they are probably occupying the same nearshore habitat as YOY during the first year of life. Density-dependent processes such as competition or predation can obscure the relationship between YOY and older year classes (Forrester 1995, Caley et al. 1996, Hixon \& Webster 2002, Samhouri et al. 2009, Hixon et al. 2012). Indeed, large year classes can attract disproportionate predation (Hobson et al. 2001). Our data were not consistent with a pattern of density dependence, which would predict a positive logistic or saturating relationship between YOY abundance and abundance of older year classes (e.g. Fontes et al. 2009). Despite the large number of YOY observed in 2006, this cohort was characterized by a low effective number of breeders and a large number of siblings (Lotterhos \& Markel 2012). Lack of genetic diversity has been linked to decreased performance of a population (e.g. Hughes et al. 2008), and in a rocky reef fish, a recent study found that low-diversity populations experienced stronger density dependence in population growth rates than high-diversity populations (Johnson et al. 2016).

Another explanation for our data may be winter mortality. Surviving the first winter of life is a critical stage in fish as well as in a diverse array of other taxa (Munch et al. 2003, Carlson et al. 2010). Storms and high wave energy may cause higher mortality or movements of juvenile and sub-adult black rockfish to deeper sites (Carr 1991, Green \& Starr 2011). In addition, wave height can be an indicator of the mortality of the kelp forest habitat that is an important refuge for juveniles (Seymour et al. 1989, Johnson 2007). Our data are consistent with the hypothesis that winter conditions experienced by YOY fish determine their survival to the OYO stage. Following the strong recruitment event of 2006, the winter of 2006-2007 was one of the worst storm seasons on record in BC (DFO 2007). A measure of storminess for that winter, the sea surface height (SSH) anomaly, measured at Point Atkinson, British Columbia, and compared to data from 1963 to 2010, was the fourth highest on record (Tinis 
2011, maximum SSH $=0.93$ and $210 \mathrm{~h}$ of SSH above

$0.4 \mathrm{~m}$ ). The winter of 2007-2008 was also stormy, with a maximum SSH of $0.82 \mathrm{~m}$ and $125 \mathrm{~h}$ with $\mathrm{SSH}$ above $0.4 \mathrm{~m}$. In contrast, favorable winter conditions during the winter of 2008-2009 may have benefited survival for the 2008 cohort. 2008-2009 was the calmest winter on record between 1963 and 2009 (Tinis 2009, maximum SSH = $0.45 \mathrm{~m}$ and only $8 \mathrm{~h}$ above $0.4 \mathrm{~m}$ ). Although 2008 YOY recruitment levels were only slightly above average, the number of OYO fish caught in the SMURFS after that very calm winter was much greater than in any other year. More years of data will be needed to support this hypothesis.

\section{Importance of habitat complexity}

Habitat complexity was a significant predictor of adult abundance in our system. Our results are consistent with those of Efird \& Konar (2014), who found substratum rugosity to be a significant predictor of fish assemblages in Alaska, USA. In other studies, black rockfish have been found on complex rock bottoms, near vertical bedrock walls, and inside or around kelp forests in high-and low-relief rocky terrain (Leaman 1976, Love et al. 2002, Johnson et al. 2003, Parker et al. 2008, Efird \& Konar 2014). Juveniles or sub-adults in our study may have migrated from shallow kelp forests into suitable (rockier) habitat.

Structurally complex habitat may also reduce mortality of juveniles by providing refuge space from predators (Johnson 2007). Johnson (2007) found that although recruitment did not vary with habitat complexity, complexity altered the mortality rates of blue rockfish recruits with a decrease in both density- dependent and density-independent mortality as complexity increased. Mortality of other YOY rockfishes has been shown to be density-dependent, as predation increases with a shortage of refuge space at high juvenile densities (Johnson 2006). Many sites in Loudoun Channel, where the majority of 2006 YOY recruited (Markel etal. 2017), also had verylow levels of habitat complexity, and mortality or post- recruitment migration may have been high at these sites. Habitatcomplexity may therefore have positive effects on fish abundance through a dampening of density-dependent processes or because sub-adults migrate into suitable habitat.

\section{Efficacy of the RCA in Barkley Sound}

Our data indicate that the abundance of inshore rockfishes was higher in the RCA compared to sites outside the RCA in both years of our survey. The BGI RCA was designated in 2004, so it had been in place for only 6 to $7 \mathrm{yr}$ at the time of sampling and can therefore be considered to be 'young' (Edgar et al. 2014). Although recruitment sites sampled in the BGI RCA in 2006 showed low levels of recruitment com-pared to sites outside, there was no significant difference in other years (Markel et al. 2017).

Although habitat quality is clearly an important MPA design and evaluation feature (Parnell et al. 2006, Claudet \& Guidetti 2010), several authors have recommended the 
utility of determining physical proxies of larval supply such as headlands that concentrate larvae (DeMartini et al. 2013) and recruitment strength (e.g. indices of upwelling, Caselle et al. 2010a) to inform conservation planning and fisheries management (Bode et al. 2012). The factors affecting black rockfish recruitment in Barkley Sound have been shown to be highly complex at the larval and settlement stage (Lotterhos \& Markel 2012, Markel et al. 2017) and as we have shown here, are also complex during the post-recruitment phase. Finding suitable indicators of recruitment to the adult population may therefore prove to be challenging in this system. However, adult black rockfish density is positively related to habitat complexity. Habitat complexity would therefore be an important criterion for the design or evaluation of RCAs. Habitat complexity and the proportion of rocky substrates are also easier to measure than fish recruitment, since they are more static, better understood, and can be modeled using bathymetry and other remotely sensed data (i.e. lampietro et al. 2008, Haggarty 2015). Furthermore, targeting protection on the life stages that are vulnerable to fishing may maximize conservation gains (Grüss et al. 2011). Our results show that the BGI RCA is effective in protecting black rockfish as well as other inshore rockfish species despite the lower levels of recruitment found by Markel et al. (2017).

\section{CONCLUSIONS}

Our results indicate that monitoring recruitment without considering postrecruitment movement, mortality, and over-wintering success may not predict the eventual effectiveness of RCAs without also considering habitat quality. Although this study took place at a fine regional scale, these results may be applicable to other temperate nearshore fish species and illustrate how moderate YOY year classes can make a disproportionate contribution to the adult population, and how habitat can be a strong predictor of adult density. Targeting high quality adult habitat for protection is therefore important. Greatest benefits will be accrued if those sites are also within close proximity to important juvenile habitats so that ontogenetic movements are supported.

\section{Acknowledgements}

We are grateful for the hard work of our diving team: Sarah Frioult, Guilia Bernardi, Jocelyn Nelson, Siobhan Gray, Rebecca Martone, and Russell Markel. Thank you to I. McGraw for providing additional black rock- fish. We also thank 3 anonymous reviewers from Axios Review for comments that greatlyimproved this manuscript, and are thankful for the advice provided by Mary O'Connor and Steve Martell. This work was funded by a Strategic NSERC grant to J.B.S. D.R.H. was funded by NSERC, a UBC Star Fellowship, and a West Canadian Universities Marine Science Centre Student Scholarship. Additional funds to K.E.L. were provided by a National Science Foundation Graduate Research Fellowship. This work was completed at the Bamfield Marine Science Centre. 


\section{LITERATURE CITED}

Allison GW, Lubchenco J, Carr MH (1998) Marine reserves are necessary but not sufficient for marine conservation. Ecol Appl 8:S79-S92

Ammann AJ (2004) SMURFs: standard monitoring units for the recruitment of temperate reef fishes. J Exp Mar Biol Ecol 299:135-154

Bode M, Armsworth PR, Fox HE, Bode L (2012) Surrogates for reef fish connectivity when designing marine protected area networks. Mar Ecol Prog Ser 466:155-166

Caley MJ, Carr MH, Hixon MA, Hughes TP, Jones GP, Menge BA (1996) Recruitment and the local dynamics of open marine populations. Annu Rev Ecol Syst 27: 477-500

Carlson SM, Kottas A, Mangel M (2010) Bayesian analysis of size-dependent overwinter mortality from size-frequency distributions. Ecology 91:1016-1024

Carr MH (1991) Habitat selection and recruitment of an assemblage of temperate zone reef fishes. J Exp Mar Biol Ecol 146:113-137

Carr MH, Reed DC (1993) Conceptual issues relevant to marine harvest refuges: examples from temperate reef fishes. Can J Fish Aquat Sci 50:2019-2028

Carr MH, Syms C (2006) Recruitment. In: Allen LG, Pondella DJ II, Horn MH (eds) The ecology of marine fishes. University of California Press, Berkeley, CA, $p$ $411-427$

Caselle JE, Carr MH, Malone DP, Wilson JR, Wendt DE (2010a) Can we predict interannual and regional variation in delivery of pelagic juveniles to nearshore populations of rockfishes (Genus Sebastes) using simple proxies of ocean conditions? Calif Coop Ocean Fish Invest Rep 51:91-105

Caselle JE, Kinlan BP, Warner RR (2010b) Temporal and spatial scales of influence on nearshore fish settlement in the Southern California Bight. Bull Mar Sci 86:355-385

Claudet J, Guidetti P (2010) Improving assessments of marine protected areas. Aquat Conserv 20:239-242

Claudet J, Osenberg CW, Domenici P, Badalamenti F and others (2010) Marine reserves: Fish life history and eco- Iogical traits matter. Ecol Appl 20:830-839 
DeMartini EE, Wren JLK, Kobayashi DR (2013) Persistent spatial patterns of recruitment in a guild of Hawaiian coral reef fishes. Mar Ecol Prog Ser 485:165-179

DFO (Fisheries and Oceans Canada) (2007) State of the Pacific Ocean 2006. Science Advisory Rep 2007/019. Canadian Science Advisory Secretariat, DFO. http://dfo- mpo.gc.ca/Library/328475.pdf

Edgar GJ, Stuart-Smith RD, Willis TJ, Kininmonth S and others (2014) Global conservation outcomes depend on marine protected areas with five key features. Nature 506:216-220

Efird TP, Konar B (2014) Habitat characteristics can in fluence fish assemblages in high latitude kelp forests. Environ Biol Fishes 97:1253-1263

Fontes J, Caselle JE, Afonso P, Santos RS (2009) Multi-scale recruitment patterns and effects on local population size of a temperate reef fish. J Fish Biol 75:1271-1286

Foreman MGG, Crawford WR, Cherniawsky JY, Galbraith J (2008) Dynamic ocean topography for the northeast Pacific and its continental margins. Geophys Res Lett 35: L22606

Forrester GE (1995) Strong density-dependent survival and recruitment regulate the abundance of a coral reef fish. Oecologia 103:275-282

Frable BW, Wagman D, Frierson TN, Aguilar A, Sidlauskas BL (2015) A new species of Sebastes (Scorpaeniformes: Sebastidae) from the northeastern Pacific, with a re-description of the blue rockfish, S. mystinus (Jordan and Gilbert, 1881). Fish Bull 113:355-377

Gaines S, White C, Carr M, Palumbi SR (2010) Designing marine reserve networks for both conservation and fisheries management. Proc Natl Acad Sci USA 107: 18286-18293

Gillanders BM, Able KW, Brown JA, Eggleston DB, Sheridan PF (2003) Evidence of connectivity between juvenile and adult habitats for mobile marine fauna: an important component of nurseries. Mar Ecol Prog Ser 247:281-295

Green KM, Starr RM (2011) Movements of small adult black rockfish: implications for the design of MPAs. Mar Ecol Prog Ser 436:219-230

Grorud-Colvert K, Sponaugle S (2009) Larval supply and juvenile recruitment of 
coral reef fishes to marine reserves and non-reserves of the upper Florida Keys, USA. Mar Biol 156:277-288

Grüss A, Kaplan DM, Guénette S, Roberts CM, Botsford LW (2011) Consequences of adult and juvenile movement for marine protected areas. Biol Conserv 144:692-702

Haggarty DR (2015) An evaluation of the effectiveness of Rockfish Conservation Areas in British Columbia, Canada. PhD dissertation, University of British Columbia, Vancouver, BC

Haggarty DR, Shurin JB, Yamanaka KL (2016) Assessing population recovery inside British Columbia's Rockfish Conservation Areas with a remotely operated vehicle. Fish Res 183:165-179

Halpern BS, Warner RR (2003) Matching marine reserve design to reserve objectives. Proc R Soc Lond B Biol Sci 270:1871-1878

Hamilton SL, Caselle JE, Malone DP, Carr MH (2010) Incorporating biogeography into evaluations of the Channel Islands marine reserve network. Proc Natl Acad Sci USA 107:18272-18277

Hedges LV, Gurevitch J, Curtis PS (1999) The meta-analysis of response ratios in experimental ecology. Ecology 80: 1150-1156

Hixon M, Webster MS (2002) Density dependence in reef fishes: coral-reef populations as model systems. In: Sale PF (ed) Coral reef fishes: dynamics and diversity in a complex ecosystem. Academic Press, San Diego, CA, p 303-325

Hixon M, Anderson TW, Buch KL, Johnson DW, Mcleod JB, Stallings CD (2012) Density dependence and population regulations in marine fish: a large-scale, long-term field manipulation. Ecol Monogr 82:467-489

Hobson ES, Chess JR, Howard DF (2001) Interannual variation in predation on first-year Sebastes spp. by three northern California predators. Fish Bull 99:292-302

Hughes AR, Inouye BD, Johnson MTJ, Underwood N, Vel- lend M (2008) Ecological consequences of genetic diversity. Ecol Lett 11:609-623

lampietro PJ, Young MA, Kvitek RG (2008) Multivariate prediction of rockfish habitat suitability in Cordell Bank National Marine Sanctuary and Del Monte Shalebeds, California, USA. Mar Geod 31:359-371 
Johnson DW (2006) Predation, habitat complexity, and variation in densitydependent mortality of temperate reef fishes. Ecology 87:1179-1188

Johnson DW (2007) Habitat complexity modifies post-settlement mortality and recruitment dynamics of a marine fish. Ecology 88:1716-1725

Johnson SW, Murphy ML, Csepp DJ (2003) Distribution, habitat, and behavior of rockfishes, Sebastes spp., in nearshore waters of southeastern Alaska:

observations from a remotely operated vehicle. Environ Biol Fishes 66: 259-270

Johnson DW, Freiwald J, Bernardi G (2016) Genetic diversity affects the strength of population regulation in a marine fish. Ecology 97:627-639

Laidig TE, Chess JR, Howard DF (2007) Relationship between abundance of juvenile rockfishes (Sebastes spp.) and environmental variables documented off north- ern California and potential mechanisms for the covariation. Fish Bull 105:39-48

Leaman BM (1976) The association between the black rock- fish (Sebastes melanops Girard) and beds of the giant kelp (Macrocystis integrifolia Bory) in Barkley Sound, British Columbia. MSc thesis, University of British Columbia, Vancouver, BC

Lotterhos KE, Markel RW (2012) Oceanographic drivers of offspring abundance may increase or decrease reproductive variance in a temperate marine fish. Mol Ecol 21: 5009-5026

Lotterhos KE, Dick SJ, Haggarty DR (2014) Evaluation of rockfish conservation area networks in the United States and Canada relative to the dispersal distance for black rockfish (Sebastes melanops). Evol Appl $7: 238-259$

Love M, Yoklavich M, Thorsteinson L (2002) The rockfishes of the Northeast Pacific. University of California Press, Los Angeles, CA

MacLellan SE (1997) How to age rockfish (Sebastes) using S. alutus as an example - the otolith burnt section technique. Can Tech Rep Fish Aquat Sci 2146

Markel RW (2011) Rockfish recruitment and trophic dynamics on the west coast of Vancouver Island: fishing, ocean climate, and sea otters. PhD dissertation, University of British Columbia, Vancouver, BC

Markel RW, Lotterhos KE, Robinson CLK (2017) Temporal variability in the environmental and geographic predictors of spatial-recruitment in nearshore 
rockfishes. Mar Ecol Prog Ser 574:97-111

McCook LJ, Ayling T, Cappo M, Choat JH and others (2010) Adaptive management of the Great Barrier Reef: a globally significant demonstration of the benefits of networks of marine reserves. Proc Natl Acad Sci USA 107: 18278-18285

Munch SB, Mangel M, Conover DO (2003) Quantifying natural selection on body size from field data: winter mortality in Menidia menidia. Ecology 84:2168-2177

Pacunski RE, Palsson WA (2001) Macro- and micro-habitat relationships of adult and sub-adult rockfish, lingcod, and kelp greenling in Puget Sound. Puget Sound Re- search 2001, Olympia, WA

Parker SJ, Rankin PS, Olson JM, Hannah RW (2007) Movement patterns of black rockfish (Sebastes melanops) in Oregon coastal waters. In: Heifetz J, Dicosimo J,

Gharrett AJ, Love MS, O'Connell VM, Stanley RD (eds) Biology, assessment, and management of North Pacific rock- fishes. Alaska Sea Grant College Program, Fairbanks, AK, p 39-57

Parker SJ, Olson JM, Rankin PS, Malvitch JS (2008) Patterns in vertical movements of black rockfish Sebastes melanops. Aquat Biol 2:57-65

Parnell PE, Dayton PL, Lennert-Cody CE, Rasmussen LL, Leichter JL (2006) Marine reserve design: optimal size, habitats, species affinities, diversity, and ocean micro- climate. Ecol Appl 16:945-962

Planes S, Galzin R, Rubies AG, Goñi R and others (2000) Effects of marine protected areas on recruitment processes with special reference to Mediterranean littoral ecosystems. Environ Conserv 27:126-143

R Development Core Team (2008) R: a language and environment for statistical computing. R Foundation for Statistical Computing, Vienna

Ralston S, Howard DF (1995) On the development of year- class strength and cohort variability in two northern California rockfishes. Fish Bull 93:710-720

Russ GR, Alcala AC (2011) Enhanced biodiversity beyond marine reserve boundaries: the cup spillith over. Ecol Appl 21:241-250

Russ GR, Stockwell B, Alcala AC (2005) Inferring versus measuring rates of recovery in no-take marine reserves. Mar Ecol Prog Ser 292:1-12

Sale PF, Cowen RK, Danilowicz BS, Jones GP and others (2005) Critical science 
gaps impede use of no-take fishery reserves. Trends Ecol Evol 20:74-80

Samhouri JF, Steele MA, Forrester GE (2009) Inter-cohort competition drives density dependence and selective mortality in a marine fish. Ecology 90:1009-1020

Seymour RJ, Tegner MJ, Dayton PK, Parnell PE (1989) Storm wave induced mortality of giant kelp, Macrocystis pyrifera, in Southern California. Estuar Coast Shelf Sci 28:277-292

Tinis S (2009) Storm surge forecasting for southwestern British Columbia: fall/winter 2008-2009. Fisheries and Oceans Canada, Victoria, BC

Tinis S (2011) Storm surge climatology for Southwestern British Columbia: fall/winter 2010-2011. Fisheries and Oceans Canada, Victoria, BC

Warner RR, Chesson PL (1985) Coexistence mediated by recruitment fluctuations: a field guide to the storage effect. Am Nat 125:769-787

Wen CKC, Almany GR, Williamson DH, Pratchett MS and others (2013) Recruitment hotspots boost the effective- ness of no-take marine reserves. Biol Conserv 166: 124-131

Yamanaka K, Logan G (2010) Developing British Columbia's inshore rockfish conservation strategy. Mar Coast Fish 2: 28-46

Yoklavich MM, Loeb VJ, Nishimoto M, Daly B (1996) Near- shore assemblages of larval rockfishes and their physical environment off central California during an extended El Niño event, 1991-1993. Fish Bull 94:766-782 